Clin. EXPL. METASTASIS, 1986, vOL. 4, No. 4, 259-272

\title{
Laminin production by murine melanoma cells: possible involvement in cell motility
}

\author{
S. E. G. FLIGIEL, K. A. LAYBOURN, B. P. PETERS, \\ R. W. RUDDON, J. C. HISERODT and J. VARANI $\dagger$ \\ The Departments of Pathology and Pharmacology, The University of Michigan \\ Medical School, Ann Arbor, Michigan 48109, U. S. A.
}

(Received 4 February 1986; accepted 14 May 1986)

\begin{abstract}
Three lines of B16 melanoma cells (B16-F1, B16-F10 and B16-BL6) were examined for motility in the micropore filter assay and for synthesis in culture of the basal lamina glycoprotein laminin. All three lines synthesized laminin as judged by the incorporation of $\left[{ }^{35} \mathrm{~S}\right]$ methionine into immunoreactive laminin and secreted (or shed) laminin into the culture medium as indicated by biosynthetic labeling studies and enzyme-linked immunosorbent assays. Immunoreactive laminin was also seen on the surface of the cells as indicated by immunofluorescence staining and by complement-mediated killing. Analysis of $\left[{ }^{35} \mathrm{~S}\right]$ methionine-labeled laminin immunoprecipitates by sodium dodecylsulfatepolyacrylamide gel electrophoresis (SDS-PAGE) both with and without reduction of intersubunit disulfide bonds revealed that all three cell lines produced a similar array of laminin forms, and that the $M_{\mathrm{r}}=950 \mathrm{kD}$ laminin molecule (but not the uncombined subunits) was secreted into the culture medium. Laminin biosynthesis appeared to be limited by the availability of the $M_{\mathrm{r}}=400 \mathrm{kD} \mathrm{A}$ subunit as shown by the intracellular accumulation of excess B subunit in the form of uncombined B subunit $\left(M_{\mathrm{r}}=200 \mathrm{kD}\right)$ and as a disulfide-linked B dimer $\left(M_{\mathrm{r}}=400 \mathrm{kD}\right)$. The motility of all three cell lines was stimulated four- to five-fold by the addition of either exogenous laminin from the EHS sarcoma or culture medium from the B16 cells containing the secreted laminin. The stimulated motility was inhibited by antilaminin serum. These observations suggest that the laminin synthesized by the B16 melanoma cells themselves may facilitate their motility.
\end{abstract}

\section{Introduction}

Active tumor cell motility is thought to contribute to the invasion process. There is a correlation between in vitro motility and in vivo behavior in a number of model systems $[3,9,19,31,32]$. Additionally, in vivo tumor cell motility has been directly demonstrated $[10,33]$, and the histological features of the tumor/host tissue interface are, in many instances, consistent with the involvement of active motility $[4,5]$.

How tumor cell motility is regulated is not fully understood. A variety of factors stimulate tumor cell motility by a chemotactic mechanism (i.e. when the stimulating agent is present in the form of a soluble gradient) and/or by a haptotactic mechanism (i.e. when the stimulating agent is present in the form of a substrate-bound gradient $[14,17,19,26,31]$. In a previous study, McCarthy and Furcht [17] reported that laminin, a basal lamina glycoprotein [8], induced haptotactic migration of B16 melanoma cells. Since B16 melanoma cells have receptors for the laminin molecule [21], this provides a possible mechanism for the adhesion to, and migration across, basement membranes by these tumor cells. In the present report we propose a

$\dagger$ To whom reprint requests should be addressed. 
second mechanism. We show here that the B16 cells, themselves, synthesize laminin. The synthesized laminin is secreted into the culture medium and bound to the cell surface. The culture fluid from the cells stimulates their motility (in the absence of a gradient) and a significant proportion of this activity is inhibited with antilaminin serum. Based on these findings, we suggest that in B16 melanoma cells, endogenous laminin promotes motility and may contribute to basement membrane invasion.

\section{Methods}

Cells

The three lines of B16 melanoma cells used in this study were the B16-F1, B16F10 and B16-BL6 lines. All three lines were provided by Dr J. Niederkorn (Department of Ophthalmology, University of Texas, Dallas, Texas). The B16-F1 and B16-F10 lines were originally isolated by Fidler [7] and the B16-BL6 line was isolated by Hart [11]. All three lines were grown using RPMI-1640 medium supplemented with 10 per cent fetal bovine serum, $100 \mathrm{U} / \mathrm{ml}$ of penicillin, $100 \mu \mathrm{g} / \mathrm{ml}$ of streptomycin and $0.25 \mu \mathrm{g} / \mathrm{ml}$ of fungizone. They were maintained at $37^{\circ} \mathrm{C}$ in $5 \mathrm{per}$ cent $\mathrm{CO}_{2}$ and subcultured by trypsinization as required. For some experiments, the JAR line of human choriocarcinoma cells was used for the purpose of comparison. The biosynthesis of laminin by these cells has been studied in detail [20]. Prior to use, all of the lines were shown to be free of mycoplasma contamination by growth in mycoplasma broth and on mycoplasma agar.

\section{Laminin and antilaminin serum}

Laminin prepared in our laboratory or purchased from Bethesda Research Laboratories (Gaithersburg, MD) was isolated from the murine Englebreth-HolmSwarm (EHS) tumor by the method of Timpl et al. [24]. The purity of each lot of laminin was confirmed by sodium dodecylsulfate-polyacrylamide gel electrophoresis (SDS-PAGE) under reducing conditions. Only two protein bands characteristic of laminin $\mathrm{A}\left(M_{\mathrm{r}}=400 \mathrm{kD}\right)$ and $\mathrm{B}\left(M_{\mathrm{r}}=200 \mathrm{kD}\right)$ subunits were seen on the gels after staining with Coomassie Brilliant Blue R250. Enzyme-linked immunosorbent assay (ELISA) [29] established that the laminin was reactive with rabbit polyclonal antilaminin antibodies (undilute to $10^{6}$ dilution) but not with rabbit polyclonal antifibronectin antibodies (provided as a generous gift by Dr. R. Wiggins, Department of Medicine, The University of Michigan) or with antitype IV collagen antibodies (provided as a generous gift by $\operatorname{Dr} \mathrm{H}$. Furthmayr, Department of Pathology, Yale University). The antifibronectin and antitype IV collagen antibodies reacted strongly with their respective antigens in ELISA. The laminin was also biologically active in a cell attachment assay at concentrations as low as $0.5 \mu \mathrm{g}$ per $35 \mathrm{~mm}$ dish [29].

Rabbit polyclonal antilaminin antiserum was prepared by the repeated intradermal injection of murine laminin into New Zealand white rabbits as described [18]. The antilaminin serum reacted with laminin by immunoblotting and by ELISA at undilute to $10^{6}$ dilution [12]. It did not react with either type IV collagen from the EHS sarcoma (Bethesda Research Laboratories) or with human plasma fibronectin (Sigma Chemical Co., St Louis, MO).

\section{Biosynthetic labeling}

The three cell lines were grown in $100 \mathrm{~mm}$ (diameter) culture dishes to an approximate density of $1 \times 10^{7}$ cells per dish. The cells were washed and incubated 
for $30 \mathrm{~min}$ in methionine-free, serum-free minimal essential medium (Flow Laboratories, McLean, VA) followed by a $60 \mathrm{~min}$ incubation in the same medium supplemented with $500 \mu \mathrm{Ci}$ per dish of $\left[{ }^{35} \mathrm{~S}\right]$ methionine $(1000-1400 \mu \mathrm{Ci} / \mu \mathrm{mol}$; NEN, Boston, MA). After the $60 \mathrm{~min}$ biosynthetic pulse, the cells were again washed and incubated for a further $4 \mathrm{~h}$ in complete medium. The $4 \mathrm{~h}$ chase cells were lysed in a solution of phosphate-buffered saline (PBS) containing three detergents (1 per cent Triton X-100, 0.5 per cent sodium deoxycholate and $0 \cdot 1$ per cent sodium dodecylsulfate; all obtained from Sigma Chemical Company) and protease inhibitors including $20 \mathrm{~mm}$ EDTA, $5 \mathrm{mM} N$-ethylmaleimide, $2 \mathrm{~mm}$ phenylmethylsulfonyl fluoride and $10 \mu \mathrm{l} / 10 \mathrm{ml}$ of a protease inhibitor cocktail containing: leupeptin, $1 \mathrm{mg} / \mathrm{ml}$; antipain, $2 \mathrm{mg} / \mathrm{ml}$; benzamidine, $10 \mathrm{mg} / \mathrm{ml}$; aprotinin, $10000 \mathrm{kallikrein-}$ inactivating units per $\mathrm{ml}$; chymostatin, $1 \mathrm{mg} / \mathrm{ml}$; and pepstatin, $1 \mathrm{mg} / \mathrm{ml}$ as described by Ronnett et al. [22] in studies on the insulin receptor. All of the protease inhibitors were obtained from Sigma Chemical Company. The $4 \mathrm{~h}$ chase media were also supplemented with the detergent/protease inhibitor mixture by adding one-fourth volume of a five-fold concentrated solution. The cell lysates and chase media were frozen at $-80^{\circ} \mathrm{C}$, thawed and clarified by ultracentrifugation $(37000 \mathrm{~g}$ for $60 \mathrm{~min})$. Immunoreactive laminin forms were precipitated with a 1:5000 dilution of the rabbit antilaminin serum and protein $\mathrm{A}$-Sepharose (Sigma Chemical Co.) according to the protocol of Ruddon et al. [23]. Normal rabbit serum served as a control. The washed immunoprecipitates were divided in half and eluted with boiling ( $5 \mathrm{~min}$ ) two-fold concentrated Laemmli SDS-PAGE sample buffer [16], either with or without 2 per cent 2-mercaptoethanol. The laminin forms were fractionated on a 3 10 per cent polyacrylamide gel employing the Laemmli system. Radioactive bands were visualized by fluorography with $E n^{3}$ Hance (NEN), exposing the dried gels to X-ray film (Kodak XAR-2) for 2-4 days.

\section{Immunofluorescence}

The tumor cells were examined for antilaminin or normal rabbit serum binding by indirect immunofluorescence one day after plating. For this, $2.0 \times 10^{5}$ cells from each line were seeded onto $20 \times 20 \mathrm{~mm}$ glass coverslips. At the time of staining, the culture medium was removed and the cells were gently washed three times in cold PBS. All subsequent steps were carried out at $4^{\circ} \mathrm{C}$. The cells were stained initially with a $1: 50$ dilution of the rabbit antilaminin serum or normal rabbit serum (45 $\mathrm{min}$ ) and then washed three times. They were then stained with a 1:50 dilution of fluorescein-conjugated swine antirabbit serum ( $45 \mathrm{~min}$ ) obtained from Accurate Scientific and Chemical Company (Westbury, NY). Following three additional rinses in PBS, the coverslips were placed on a glass slide and viewed immediately by standard fluorescence microscopic techniques.

\section{Complement-mediated cytotoxicity}

We used both a direct and an indirect complement-mediated killing assay to identify laminin on the surface of viable cells. For the direct assay, the cells were harvested from culture, washed and plated at $2.5 \times 10^{5}$ cells in $0.5 \mathrm{ml}$ of medium containing $50 \mu \mathrm{l}$ of rabbit complement (Low-Tox Rabbit Complement, Accurate Chemical and Scientific Co.) and various amounts of the antilaminin serum or normal rabbit serum. One hour later, the treated cells were harvested and the number of viable cells determined using trypan blue exclusion. For the indirect test, various amounts of each cell type were incubated for $1 \mathrm{~h}$ with $100 \mu \mathrm{l}$ of the 
antilaminin serum. Following this, the absorbed sera as well as the unabsorbed control serum were examined for toxicity using the B16-F1 cells as the target. The killing assay was carried out exactly as with the direct test. That is, $2.5 \times 10^{5}$ cells were incubated for one hour at $37^{\circ} \mathrm{C}$ in the presence of $0.5 \mathrm{ml}$ of medium, $50 \mu \mathrm{l}$ of the rabbit complement and $50 \mu \mathrm{l}$ of the serum. Following this, the number of viable cells was determined.

\section{Enzyme-linked immunosorbent assay (ELISA)}

ELISAs were performed to quantify the amount of laminin secreted into the supernatant fluids by the cells. The cells were plated at $1-2 \times 10^{6}$ cells per $5 \mathrm{ml}$ of culture medium (RPMI-1640 medium containing 10 per cent fetal bovine serum) in culture flasks. After incubation for three days at $37^{\circ} \mathrm{C}$, the supernatant fluids were harvested and clarified by low-speed centrifugation. The supernatant fluids were then added to the wells of a 96-well plate (Falcon Plastics, Oxnard, CA) from lots which has been prescreened for acceptibility in ELISA reactions. We used $200 \mu \mathrm{l}$ per well and incubated the wells with the supernatant fluids for four hours at $37^{\circ} \mathrm{C}$. Control culture medium which had been preincubated for three days along with the cells served as the control. Purified EHS laminin (0.5-0.0005 $\mu \mathrm{g} /$ well) was also added to the assay plate in culture medium to serve as a standard. After the four-hour incubation, the supernatant fluids from the cells and the control fluids were removed from the assay plate and the ELISA was then run exactly as described previously [29]. The cells from which the supernatant fluids were obtained, were harvested with trypsin and counted.

\section{Motility}

Cell motility was assessed using the micropore filter method [25]. The micropore filter assay measures cell migration into the interstices of a porous filter. The filters were $12 \mu \mathrm{m}$ pore diameter, $13 \mathrm{~mm}$ nitrocellulose filters obtained from Schleicher \& Schuell, Inc. (Keene, NH). The assay medium consisted of serum-free RPMI-1640 medium supplemented with $200 \mu \mathrm{g} / \mathrm{ml}$ of bovine serum albumin or with 10 per cent fetal bovine serum. Some of the filters were pretreated overnight with $50 \mu \mathrm{g}$ of laminin in serum-free medium. When this was done, the filters were placed in the blind-well chamber and the laminin was added to the upper well. The next day, the filters were washed two times with serum-free medium to remove unbound laminin, inverted to form a gradient and used. At the time of assay, the cells were harvested from culture, washed and added to the wells at $3 \times 10^{5}$ cells per well. The cells were allowed to migrate for $4 \mathrm{~h}$ at $37^{\circ} \mathrm{C}$ following which the filters were stained with hematoxylin and examined microscopically for migration.

\section{Results}

\section{Laminin production and secretion: evidence from biosynthetic labeling studies}

Laminin production was evaluated by the incorporation of $\left[{ }^{35} \mathrm{~S}\right]$ methionine into immunoreactive forms that were precipitated from both the cell lysates and the chase medium and analysed by SDS-PAGE (figure 1). The three cell lines produced similar laminin forms but differed in the amount of $\left[{ }^{35} \mathrm{~S}\right]$ methionine incorporated into immunoreactive laminin during a $1 \mathrm{~h}$ pulse, $4 \mathrm{~h}$ chase protocol. Analysis of the laminin immunoprecipitates from the cell lysates by SDS-PAGE under nonreducing conditions (figure 1 , top panel, lanes designated A) to preserve intersubunit 
disulfide bonds revealed three principal laminin bands that were absent from the non-immune rabbit serum controls (lanes designated B). These cellular laminin forms migrated similarly on the SDS gel to the assembled laminin molecule $\left(M_{\mathrm{r}}=950 \mathrm{kD}\right)$ and to the $400 \mathrm{kD}$ and $200 \mathrm{kD}$ subunits. Under non-reducing conditions, it is likely that the $400 \mathrm{kD}$ band represents a disulfide-linked dimer of the laminin B subunit $\left(M_{\mathrm{r}}=200 \mathrm{kD}\right)$ as has been shown previously to be the case with lysates of the human choriocarcinoma (JAR) cell line [20] and that the $200 \mathrm{kD}$ band represents the uncombined $B$ subunit. Consistent with this interpretation, most of the immunoreactive $\left[{ }^{35} \mathrm{~S}\right]$ methionine in the $\mathrm{B} 16$ cell lysates was seen to migrate like the laminin B subunit $\left(M_{\mathrm{r}}=200 \mathrm{kD}\right)$ upon reduction with 2-mercaptoethanol (figure 1 , middle panel); only traces of the A subunit were seen in the cell lystates at this time. This suggests that the B16 cells produce laminin B subunit forms in excess of $A$ subunit forms such that uncombined B and B dimer forms accumulate in the chase cells (figure 1, top panel). Analysis of the $4 \mathrm{~h}$ chase media revealed that nearly all of the immunoreactive laminin secreted by the three B16 lines was in the form of the assembled molecule (figure 1, lower panel). Only traces of the incompletely assembled laminin forms were secreted; this is in agreement with our previous findings with JAR choriocarcinoma cells [20] that laminin assembly is a prerequisite for secretion.

It is of interest to note that while a single distinct $\left(M_{\mathrm{r}}=950 \mathrm{kD}\right)$ laminin band was seen with the JAR cells, multiple laminin bands that migrated slightly more rapidly could be observed at the $M_{\mathrm{r}}=950 \mathrm{kD}$ locus in the case of the melanoma cell lysates and chase media. This could be due to partial proteolytic cleavage of laminin in the B16 lysates even though a panel of nine protease inhibitors was included in the lysis buffer (see Methods). Alternatively, proteolytic clipping of laminin may have occurred in the cultures before the cells were harvested, or the multiple bands might represent other post-translational processing differences such as glycosylation of the laminin molecule.

\section{Laminin secretion: ELISA data}

The amount of laminin secreted into the supernatant fluid by the three lines was also quantified using ELISA methodology. When examined at a single time point (i.e. three days after plating), the supernatant fluids from the B16-F1 and B16-BL6 lines contained comparable amounts of immunoreactive material. Based on the comparison with the standard curve, we estimate that the supernatant fluid from the B16-F1 culture contained $97 \mathrm{ng}$ of laminin per $1 \times 10^{5}$ cells and the supernatant fluid from the B16-BL6 culture contained $100 \mathrm{ng}$ per $1 \times 10^{5}$ cells (table 1 ). The supernatant fluid from the B16-F10 line contained a smaller amount (58 ng). Under the conditions in which the cells were incubated for this study (i.e. $1-2 \times 10^{6}$ cells plated per flask on day 0 ) cell growth was comparable for all three lines. By day 3 , there was 6.6-6.8 $\times 10^{6}$ cells per flask. Therefore, the differences in laminin production between the B16-F10 cells and the other two lines are not reflective of growth rate differences.

\section{Cell surface laminin: evidence from immunofluorescence and complement-mediated cytotoxicity studies}

The cells were examined in the viable state for the expression of surface laminin by immunofluorescence. All three lines stained brightly when incubated with a $1: 50$ dilution of the antilaminin serum and there was virtually no staining with the normal 
S. E. G. Fligiel et al.
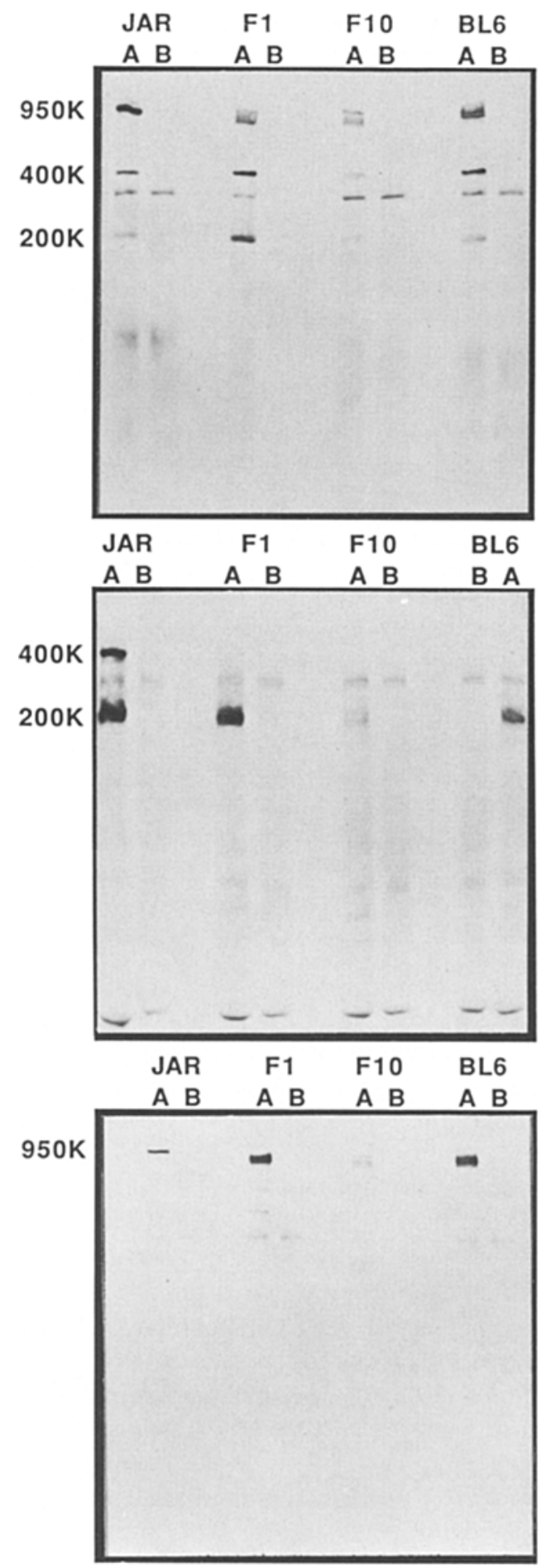
Table 1. Quantification by ELISA of laminin in the extracellular fluid from cultures of the B16 melanoma cells ${ }^{a}$.

\begin{tabular}{lc}
\hline Cell line & $\begin{array}{c}\text { Laminin } \\
\left(\mathrm{ng} / 10^{5} \text { cells }\right)^{b}\end{array}$ \\
\hline B16-F1 & $97 \cdot 0 \pm 3 \cdot 4$ \\
B16-F10 & $57 \cdot 9 \pm 7 \cdot 0$ \\
B16-BL6 & $100 \cdot 0 \pm 2 \cdot 4$ \\
\hline
\end{tabular}

${ }^{a}$ Immunoreactive laminin in the supernatant fluids from the three lines was determined by ELISA $72 \mathrm{~h}$ after plating of the cells. The values were determined by a direct comparison with a standard curve prepared using various amounts of laminin purified from the EHS sarcoma.

${ }^{b}$ The values shown are averages of duplicate readings \pm the difference between the individual values and the average values in a single experiment. The experiment was carried out seven times with very similar results.

rabbit serum at the same concentration (figure 2). While it is difficult to make quantitative comparisons based on immunofluorescence, it appeared that B16-F1 and B16-BL6 lines fluoresced with about equal intensity while the B16-F10 line fluoresced less intensely.

The presence of surface laminin on the three cell lines was also demonstrated by the cytotoxicity experiments. All three lines were killed by the antilaminin serum in the presence of complement in the direct assay and all three lines inhibited killing of the B16-F1 cells in the indirect assay (figure 3).

\section{Cell motility}

The three cell lines were examined for motility in the micropore filter assay. A comparison of the three cell lines is shown in table 2 . All three lines were motile both in the presence of serum and under serum-free conditions. When compared to one another, the B16-F1 cells and the B16-BL6 cells were consistently more motile than the B16-F10 cells.

The motility of the B16 melanoma cells was stimulated by exogenous laminin. As shown in table 3 with the B16-F1 cells, the addition of $50 \mu \mathrm{g}$ of exogenous EHS laminin to the upper well of the chamber significantly increased migration. Although not shown, the addition of $50 \mu \mathrm{g}$ of laminin to the lower well of the chamber or pretreatment of the filters with this amount of laminin also stimulated migration. Dose-response studies with laminin indicated that as little as $1.0 \mu \mathrm{g}$ of laminin added

Figure 1. Analysis by SDS-PAGE of laminin immunoprecipitates from biosynthetically labeled B16 cells and JAR choriocarcinoma cells. Cells $\left(1 \times 10^{7}\right)$ in $100 \mathrm{~mm}$ dishes were pulsed for $1 \mathrm{~h}$ with $\left[{ }^{35} \mathrm{~S}\right.$ ]methionine and chased for $4 \mathrm{~h}$ in the absence of labeled methionine. Cell lysates and chase media were divided in half and immunoprecipitated either with antilaminin serum or with non-immune rabbit serum as a control. Half of each immunoprecipitate was reduced with 2 -mercaptoethanol ( 2 per cent) and half was not. The immunoprecipitates were then analysed by SDS-PAGE on a 3-10 per cent plyacrylamide gradient slab gel. Radioactive bands were visualized by fluorography after a two-day exposure. The top panel is the non-reduced material from the cell lysates. The middle panel is the reduced material from the cell lysates and the lower panel is the non-reduced material from the chase medium. With each cell type, lane $A$ is the material immunoprecipitated with antilaminin and lane $B$ is the material precipitated with normal rabbit serum. 

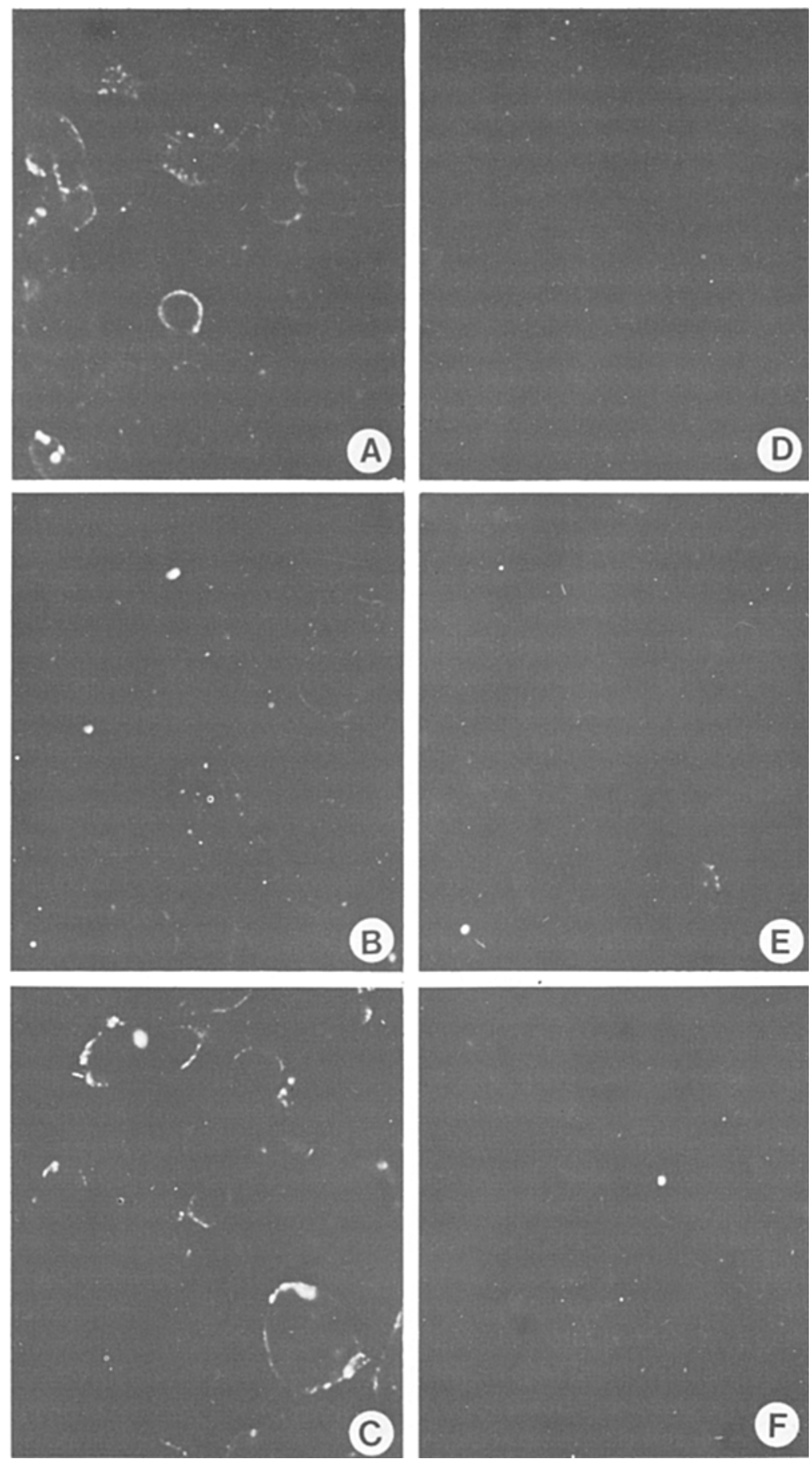

Figure 2. Immunofluorescence staining of the B16 melanoma cells in the viable state. Cells grown on coverslips for one day were gently washed in PBS and then stained at $4^{\circ} \mathrm{C}$ with a $1: 50$ dilution of the antilaminin serum or normal rabbit serum followed by a $1: 50$ dilution of the fluorescein isothiocyanate-conjugated swine antirabbit IgG. The B16$F 1$ cells are shown in panels $A$ and $D$, the B16-F10 cells are shown in panels $B$ and $E$ and the B16-BL6 cells are shown in panels $C$ and $F$. Cells stained with the antilaminin serum are shown in panels A, B and C. Cells stained with normal rabbit serum are shown in panels D, E and F. All photographs are $5 \mathrm{~min}$ exposures at $\times 400$. The three lines were examined on four separate occasions with similar results. 


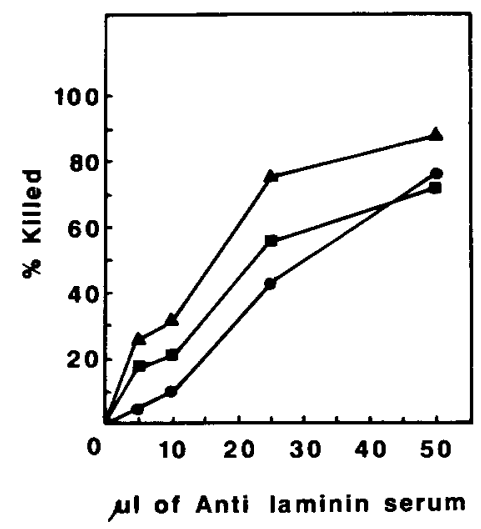

(a)

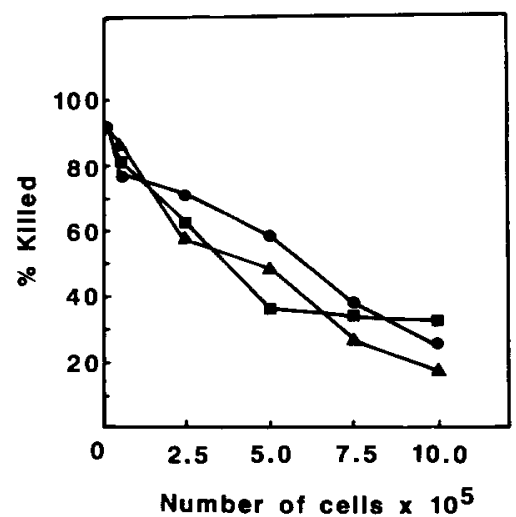

(b)

Figure 3. Complement-mediated killing of the B16 melanoma cells. (a) Direct assay: $5 \times 10^{5}$ cells were harvested, washed and plated in $0.5 \mathrm{ml}$ of medium containing $50 \mu \mathrm{l}$ of complement and various amounts of the antilaminin serum or normal rabbit serum. One hour later, the number of remaining cells was determined. (b) Indirect assay: various amounts of cells were harvested and incubated for one hour with $100 \mu \mathrm{l}$ of the antilaminin serum. Following this, the cells were separated from the serum by centrifugation and the adsorbed serum analysed for residual killing activity against the B16-F1 cells in the presence of complement. The values shown in both panels are averages of duplicate values where the individual values were within 10 per cent of the average. Both the direct and indirect assays were carried out on three separate occasions

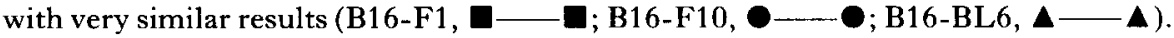

to the upper well along with the cells was sufficient to increase motility consistently. The addition of antilaminin serum ( $25 \mu \mathrm{l}$ per well) inhibited the laminin-stimulated motility (table 3 ).

Motility was also stimulated by the supernatant fluids from growing cultures of the B16 cells (table 3). These supernatant fluids are know to contain laminin, as indicated both by the metabolic labeling experiments and the ELISA studies. We

Table 2. Migration of B16 melanoma cells in the micropore filter assay ${ }^{a}$.

\begin{tabular}{clc}
\hline Cell line & \multicolumn{1}{c}{ Condition } & $\begin{array}{c}\text { Number of migrated } \\
\text { cells per high- } \\
\text { power field }\end{array}$ \\
\hline B16F1 & Serum-free & $14 \pm 1$ \\
& 10 per cent FBS & $25 \pm 3$ \\
B16-F10 & Serum-free & $2 \pm 1$ \\
& 10 per cent FBS & $12 \pm 3$ \\
B16-BL6 & Serum-free & $12 \pm 1$ \\
& 10 per cent FBS & $32 \pm 2$ \\
\hline
\end{tabular}

a The motility assay was run in RPMI -1640 medium supplemented either with $200 \mu \mathrm{g} / \mathrm{ml}$ bovine serum albumin or 10 per cent fetal bovine serum. The values shown are the mean number of migrated cells per high-power field \pm the standard error of the mean based on four fields per filter and three filters per group. The experiment was carried out three times with very similar results. When compared using a Student $t$-test, the motility of the B16-F10 cells was statistically lower than the motility of the B16-F1 cells under both serum-free conditions $(P<0.01)$ and in the presence of 10 per cent serum $(P<0 \cdot 05)$. 
Table 3. Modulation of B16 melanoma cell migration.

\begin{tabular}{lc}
\hline \multicolumn{1}{c}{ Treatment } & $\begin{array}{c}\text { Number of migrated cells } \\
\text { per high-power field }\end{array}$ \\
\hline${\text { RPMI-10 per cent } \text { FBS }^{f}}^{a}$ & $35 \pm 4$ \\
Laminin (upper well) $^{b}$ & $78 \pm 14$ \\
Laminin + antilaminin $^{c}$ & $37 \pm 5$ \\
Laminin + normal rabbit serum $_{\text {B16-F1 supernatant }}{ }^{d}$ & $60 \pm 6$ \\
B16-F1 supernatant + antilaminin & $82 \pm 9$ \\
B16-F1 supernatant + normal rabbit serum & $45 \pm 2$ \\
B16-F10 supernatant & \\
B16-F10 supernatant + antilaminin & $68 \pm 7$ \\
B16-F10 supernatant + normal rabbit serum & $78 \pm 14$ \\
\hline
\end{tabular}

a The medium consisted of RPMI-1640 medium supplemented with 10 per cent fetal bovine serum.

${ }^{b}$ Laminin $(25 \mu \mathrm{g}$ per well) was added to the upper wells of the chamber along with the cells.

'Antilaminin serum or normal rabbit serum $(25 \mu$ per well) was added to the upper wells of the chamber along with the cells.

${ }^{d}$ The B16-F1 supernatant containing approximately $200 \mathrm{ng}$ of laminin per $100 \mu \mathrm{l}$ of medium (as indicated by ELISA) was obtained from dense cultures of B16-F1 cells after $72 \mathrm{~h}$ of incubation.

e The B16-F10 supernatant containing approximately $200 \mathrm{ng}$ of laminin per $100 \mu \mathrm{l}$ of culture medium (as indicated by ELISA) was obtained from dense cultures of B16-F10 cells after $72 \mathrm{~h}$ of incubation.

${ }^{f}$ The B16-F1 cells were used as the indicator cells in these experiments. The values shown are mean number of migrated cells per high-power field \pm the standard error of the mean based on four fields per filter and three filters per group. The experiment was carried out three times with very similar results.

estimate that the supernatant fluids used in these assays contained approximately $200 \mathrm{ng}$ of laminin per $100 \mu \mathrm{l}$ (the amount used in the motility assay) based on ELISA. That at least some of the stimulation was due to the presence of laminin in these fluids was suggested by the finding that a significant proportion of the increased motility could be blocked with the antilaminin serum but not with the normal rabbit serum (table 3). The B16-F10 cells and B16-BL6 cells showed the same response to exogenous EHS laminin and to B16 culture supernatant fluids as the B16-F1 cells. That is, both the laminin and the supernatant fluids stimulated migration and the migration was inhibited with the antilaminin serum (data not shown).

\section{Discussion}

These studies examined the production of laminin by three lines of B16 melanoma cells and the possible involvement of this material in the regulation of cell motility. While we are not the first to demonstrate laminin production by cells $[1,2,6,13,15,18,20]$, we used a variety of approaches to document that all three of the B16 lines synthesized laminin and secreted it into the culture supernatant fluid. The cells also have laminin bound to their surface. While the B16-F1 and B16-BL6 cells expressed comparable amounts of surface laminin, as judged by immunofluorescence (figure 2) and secreted comparable amounts into the culture medium, as judged by biosynthetic labeling (figure 1) and ELISA (table 1), the less-motile B16F10 cells appeared to express less surface laminin and to secrete less immunoreactive material into the culture fluid. All three melanoma lines biosynthesized a similar 
array of immunoreactive laminin forms. Immunoprecipitates of the $4 \mathrm{~h}$ chase cell lysates and media contained a prominent $M_{\mathrm{r}}=950 \mathrm{kD}$ form corresponding to the assembled laminin molecule, as shown by non-reduced SDS-PAGE (figure 1, top and bottom panels). In addition, cell lysates but not media contained $200 \mathrm{kD}$ and $400 \mathrm{kD}$ forms (figure 1, top panel) that co-migrated with the uncombined B subunit and the disulfide-linked B dimer of JAR choriocarcinoma cells [20]. The identity of these bands was further substantiated by the observation that the cellular immunoprecipitates contained mainly the B subunit as indicated by analysis on a reduced SDS gel (figure 1, middle panel). This is consistent with our previous interpretation that laminin synthesis in JAR cells is limited by the availability of A subunit and appears to be true even more in the B16 cells. We cannot, however, completely rule out the possibility that some A subunit was lost due to proteolysis in the B16 lysates, even though a battery of nine protease inhibitors was added to the lysis buffer. As is the case in the JAR cultures [20], only the assembled $\left(M_{\mathrm{r}}=950 \mathrm{kD}\right)$ laminin molecule was secreted into the B16 chase media, suggesting that assembly is a prerequisite for laminin secretion.

In addition to characterizing laminin forms biosynthesized by the B16 melanoma cells, these studies provide evidence that laminin produced by the cells influences their migration. Previous studies have shown that the addition of exogenous laminin stimulates the migration of the B16 cell lines [17] as well as other cells [31]. Laminin is found as a constituent of basement membranes [8], and the B16 cells have receptors for the laminin molecule [21]. Therefore, the interaction of cells via their receptors with laminin in the basement membranes provides a mechanism whereby the invading tumor cells could use the exogenous laminin to traverse basement membranes. While our data in no way disagree with this idea, they suggest a second mechanism through which laminin may act to facilitate cell motility. Since these cells are a biosynthetic source of laminin and produce amounts sufficient to stimulate motility, the laminin produced by the B16 cells, themselves, may facilitate their motility. This may be likened to the autocrine stimulation of cell proliferation by endogenous synthesis of growth promoting peptides. In support of this hypothesis: (1) all three of the cell lines produced significant amounts of laminin and all three lines were highly motile; (2) the supernatant fluids, containing laminin secreted by the cells, stimulated motility; and (3) the stimulated motility was inhibited with antilaminin serum. The inhibition of stimulated motility with the antilaminin suggests that the antibodies inhibit laminin binding to the cells. Alternatively, the antilaminin antibodies could interfere with motility by binding to cell surface laminin and inhibiting its function.

One question that must be addressed concerns the differences between the more highly motile B16-F1 and B16-BL6 lines and the less motile B16-F10 line. The SDS gels in figure 1 revealed no qualitative differences in the array of laminin forms produced by the three lines. Therefore, we cannot at this time ascribe the motility differences to the production of biochemically different laminin forms. The basal motility of the three melanoma lines does appear to be related to the amount of laminin they produce. However, the differences between the B16-F10 cells and the other two lines is probably not simply a question of the amount of laminin produced since the motility differences persist even at exogenous laminin concentrations as high as $50 \mu \mathrm{g}$ per reaction. Certainly, other factors may be involved.

Perhaps more important than comparing the three melanoma lines among themselves is to compare all three lines to other cells that have been examined. Our 
previous studies have focused on a series of highly malignant and low malignant cell lines derived from carcinogen-induced murine fibrosarcomas. The highly malignant fibrosarcoma cell lines were shown to be more motile than the low malignant lines under a variety of conditions $[19,31]$. The migration of the highly malignant fibrosarcoma cells was comparable to that shown here for all three melanoma lines. The highly malignant fibrosarcoma cells were also like the melanoma cells, and different from the low malignant fibrosarcoma cells, in that they produced detectable quantities of laminin $[18,29,30]$. Thus, the findings made with the $\mathrm{B} 16$ cells in the present study are consistent with the findings regarding laminin synthesis and motility made previously with the fibrosarcoma cells. It should also be noted that in regard to in vivo behavior, the highly malignant fibrosarcoma cells are again like the B16 cells, and different from the low malignant fibrosarcoma cells, in that they spontaneously metastasize from primary tumors and form lung colonies after intravenous injection [27, 28]. Thus, although there are likely to be a number of differences among the B16 lines unrelated to laminin which contribute to differences in lung colonizing ability, the finding that all three lines synthesize laminin is consistent with the previously proposed hypothesis regarding laminin expression and in vivo behavior.

In summary, these studies demonstrate the synthesis of laminin by B16 melanoma cells, its binding to the cell surface and secretion into the extracellular medium. These studies confirm earlier reports demonstrating that laminin stimulates B16 cell motility and suggest that the endogenous laminin produced by the tumor cell, themselves, may play a role in facilitating their motility. Previous studies have demonstrated the production of laminin by various cells. Our data support the concept that the laminin produced by the cells has biological importance.

\section{Acknowledgment}

This study was supported in part by grants CA36132 and CA32949 from the U.S.P.H.S.

\section{References}

[1] Albrechtsen, R., Nielson, M., Wewer, U., Engvall, E., and Ruoslahti, E., 1981, Basement membrane changes in breast cancer detected by immunochemical staining for laminin. Cancer Research, 41, 5076-5081.

[2] Alitalo, K., Kuismanen, E., Myllyla, R., Kiistala, U., Asko-Seljavaara, S., and VAHERI, A., 1982, Extracellular matrix proteins of human epidermal keratinocytes and feeder 3T3 cells. Journal of Cell Biology, 94, 497-505.

[3] Barski, G., and Belehradek, J., Jr, 1965, E'tude microcinematographique du mecanisme d'invasion cancereuse en cultures de tissue normal associe aux cellules malignes. Experimental Cell Research, 37, 464480.

[4] Carr, J., Carr, I., Dreker, B., and BetTs, K., 1980, Lymphatic metastasis; invasion of lymphatic vessels and efflux of tumor cells in the afferent popliteal lymph as seen in the Walker rat carcinoma. Journal of Pathology, 132, 287-293.

[5] CARR, I., 1983, Experimental lymphatic metastasis. Journal of Microscopy, 131, 211-220.

[6] Cooper, A. R., Kurkinen, M., Taylor, A., and Hogan, B., 1981, Studies on the biosynthesis of laminin by murine parietal endoderm cells. European Journal of Biochemistry, 119, 189-197.

[7] FidLer, I. J., 1973, Selection of successive tumor lines for metastasis. Nature New Biology, 242, 148-149. 
[8] Foidart, J. M., Bere, J. J., Paglia, L., Rennard, S. I., Gullino, M., Martin, G. R., and Katz, S. I., 1980, Distribution and immunoelectron microscopic localization of laminin, a noncollagenous basement membrane glycoprotein. Laboratory Investigation, 42, 336-342.

[9] Goldrosen, M. H., and Maslow, D. E., 1985, Relationship between the colonization potential of murine colon adenocarcinoma-38 (MCA-38) cells and in vitro motility. Proceedings of the American Association for Cancer Research, 26, 57.

[10] Haemmerli, G., and Strauli, P., 1978, Motility of L5222 leukemia cells within the mesentery. A study of time-lapse cinematography. Virchows Archiv B. Cell Pathology, $29,167-171$.

[11] HART, I. R., 1979, The selection and characterization of an invasive variant of the B16 melanoma. American Journal of Pathology, 97, 585-600.

[12] Hiserodt, J. C., Laybourn, K. A., and Varani, J., 1985, Expression of a laminin-like substance on the surface of murine natural killer (NK) lymphocytes and its role in NK recognition of tumor target cells. Journal of Immunology, 135, 1484-1487.

[13] Howe, C. C., and Solter, D., 1981, Identification of non-collagenous basement membrane glycopeptides synthesized by mouse parietal endoderm and an endodermal cell line. Developmental Biology, 77, 480-487.

[14] Hujanen, E. S., and Terranova, V. P., 1985, Migration of tumor cells to organ-derived chemoattractants. Cancer Research, 45, 3517-3521.

[15] Kuhl, U., Timpl, R., and von Der MarK, K., 1982, Synthesis of type IV collagen and laminin in cultures of skeletal muscle cells and their assembly on the surface of myotubes. Developmental Biology, 93, 344-354.

[16] LAEMmLI, U. K., 1970, Cleavage of structural proteins during the assembly of the head of bacteriophage T4. Nature, 227, 680-685.

[17] McCarthy, J. B., and Furcht, L. T., 1984, Laminin and fibronectin promote the haptotactic migration of B16 melanoma cells in vitro. Journal of Cell Biology, 98, $1474-1480$.

[18] McCoy, J. P., Lloyd, R. V., Wicha, M. S., and Varani, J., Identification of a lamininlike substance on the surface of high-malignant murine fibrosarcoma cells. Journal of Cell Science, 65, 139-151.

[19] Orr, F. W., Varani, J., Delikatny, J., Jain, N., and Ward, P. A., 1981, Comparison of the chemotactic responsiveness of fibrosarcoma subpopulations of differing malignancy. American Journal of Pathology, 102, 160-167.

[20] Peters, B. P., Hartle, R. J., Krzesicki, R. F., Kroll, T. G., Perini, F., Balun, J. E., Goldstein, I. J., and Ruddon, R. W., 1985, The biosynthesis, processing and secretion of laminin by human carcinoma cells. Journal of Biological Chemistry, 260, 14732-14743.

[21] Rao, N. C., Barsky, S. H., Terranova, V. P., and Liotta, L. A., 1983, Isolation of a tumor cell laminin receptor. Biochemical and Biophysical Research Communications, 111, 804-808.

[22] Ronnett, G. V., Knutson, V. P., Kohanski, R. A., Simpson, T. L., and Lane, M. D., 1984, Role of glycosylation in the processing of newly translated insulin proreceptor in 3T3-L1 adipocytes. Journal of Biological Chemistry, 259, 4566-4575.

[23] Ruddon, R. W., Hanson, C. A., and Addison, N. J., 1979, Synthesis and processing of human chorionic gonadotropin subunits in cultured choriocarcinoma cells. Proceedings of the National Academy of Sciences, U.S.A., 76, 5143-5147.

[24] Timpl, R., Rohde, H., Robey, P. G., Rennard, S. I., Foidart, J. M., and Martin, G. R., 1979, Laminin-a glycoprotein from basement membranes. Journal of Biological Chemistry, 254, 9933-9937.

[25] VArani, J., OrR, W., and WARd, P. A., 1978, A comparison of the migration of normal and malignant cells in two assay systems. American Journal of Pathology, 90, 159-172.

[26] Varani, J., 1982, Chemotaxis of metastatic tumor cells. Cancer Metastasis Reviews, 1, $17-28$.

[27] VARANi, J., OrR, W., and Ward, P. A., 1979, Hydrolytic enzyme activities, migratory activity and in vivo growth and metastatic potential of recent tumor isolates. Cancer Research, 39, 2376-2380.

[28] Varani, J., Lovett, E. J., Elgeraly, S., Lundy, J., and Ward, P. A., 1980, In vitro and in vivo adherence of tumor cell variants correlated with tumor formation. American Journal of Pathology, 101, 345-352. 
[29] Varani, J., Lovett, E. J., McCoy, J. P., Shibata, S., Maddox, D. E., Goldstein, I. J., and WICHA, M., 1983, Differential expression of a laminin-like substance by high and low metastatic tumor cells. American Journal of Pathology, 111, 27-34.

[30] Varani, J., Lovett, E. J., Wicha, M., Malinoff, H., and McCoy, J. P., 1983 a, Cell surface $\alpha$-D-galactopyranosyl end groups: use as a marker in the isolation of murine tumor cell lines with varying malignant potential. Journal of the National Cancer Institute, 71, 1251-1286.

[31] Varani, J., Fligiel, S. E. G., and Perone, P., 1985, Directional motility in strongly malignant murine tumor cells. International Journal of Cancer, 35, 559-564.

[32] VeSELY, P., and WeISs, R. A., 1973, Cell locomotion and contact inhibition of normal and neoplastic rat cells. International Journal of Cancer, 11, 64-76.

[33] Wood, S., 1958, Pathogenesis of metastasis formation observed in vivo in the rabbit ear chamber. Archives of Pathology, 66, 550-568. 